\title{
Critical Parameters Effecting the Rapid Prototyping Surface Finish
}

\author{
P. Vijay ${ }^{1, *}$, P. Danaiah ${ }^{2}$, K. V. D. Rajesh ${ }^{1}$ \\ ${ }^{1}$ K.L.University, Green fields, Vaddeswaram, Guntur, Andhra Pradesh \\ ${ }^{2}$ N.I.T.Warangal, Andhra Pradesh
}

\begin{abstract}
A component can be manufactured in several ways. Rapid Prototyping technique is one among the material adding manufacturing process, building up its unique potential in the present scenario. This technique helps manufacture a product from the basic design of the component, thus optimizing the iterative product development process time and creating geometrically complex parts to precise dimensions. In the Rapid Prototyping process, surface finish is critical as it can affect the part accuracy, reduce the post-processing costs and improve the functionality of the parts. This paper presents an experimental design technique for determining the optimal surface finish of a part built by varying Build Orientation, Layer Thickness and keeping other parameters constant using the Fused Deposition Modeling (FDM) process. The design investigates the effect of these parameters on the surface finish. Experiments were conducted using a fractional factorial design with two levels for Layer Thickness and three levels for Build Orientation factor. The results are statistically analyzed to determine the significant factors and their interactions. The significant factors, their interactions and the optimum settings are proposed.
\end{abstract}

\section{Keywords Rapid Prototyping, Post-Processing, FDM Process}

\section{Introduction}

There are several ways to manufacture a component. Manufacturing is turning raw materials to finished products to be used for various purposes. The demand of a product depends on its performance by way of desirable exotic properties like resistance to high temperature, higher operating speeds, extra loads, economics and the surface finish. To be viable in the modern environment, a product has to be competitively priced besides having the functional and aesthetic appeal. This requirement shows the necessity for the engineer to give a proper thought to various aspects of manufacturing. Manufacturing processes can be classified into three types: material adding process-RP comes under this category, material subtracting process-which include turning, drilling, and shaping e.t.c., neither adding nor subtracting material-which include processes like forging, extrusion, coining, wire drawing, other sheet metal operations.In product development, time pressure has been a major factor in determining the direction of the development and success of new methodologies and technologies for enhancing its performance. These also have a direct impact on the age-old practice of prototyping in the product development process. One such development is Rapid Prototyping

* Corresponding author:

vijay.me250@gmail.com (P. Vijay)

Published online at http://journal.sapub.org/jmea

Copyright (C) 2011 Scientific \& Academic Publishing. All Rights Reserved
(RP).

\section{Types of Prototypes}

The general definition of prototype deals with three aspects of interests

- The implementation of the prototype from the entire product itself to its subassemblies and components.

- The form of the prototype from a virtual to a physical prototype.

- The degree of the approximation of the prototype from a rough representation to an exact replication of the product.

\section{Historical Development}

The development of rapid prototyping is closely tied in with the development of applications of computers in the industry. The declining cost of computers, especially of personal and mini computers has changed the way of factory works. The increase in the use of computers has spurred the advancement in many computer-related areas including Computer-Aided Design (CAD), Computer- AIDED Manufacturing (CAM) and Computer Numerical Control (CNC) machine tools. In particular, the emergence of RP systems in existence today, can be easily deduced that other then CAD, many other technologies advancements in fields such as manufacturing systems and materials have also been crucial in the development of RP systems. Table given below traces 
the historical development of relevant technologies related to RP from the date of inspection.

Table 1. Historical developments of Rapid prototyping and related technologies

\begin{tabular}{|c|c|}
\hline Year of Inception & Technology \\
\hline 1770 & Mechanization \\
\hline 1946 & First Computer \\
\hline 1952 & First Numerical Control Machine Tool \\
\hline 1960 & First Commercial Laser \\
\hline 1961 & First commercial Robot \\
\hline 1963 & First interactive Graphics System \\
\hline 1988 & First Commercial Rapid Prototyping System \\
\hline
\end{tabular}

\section{Design}

An outline of the procedure is shown below

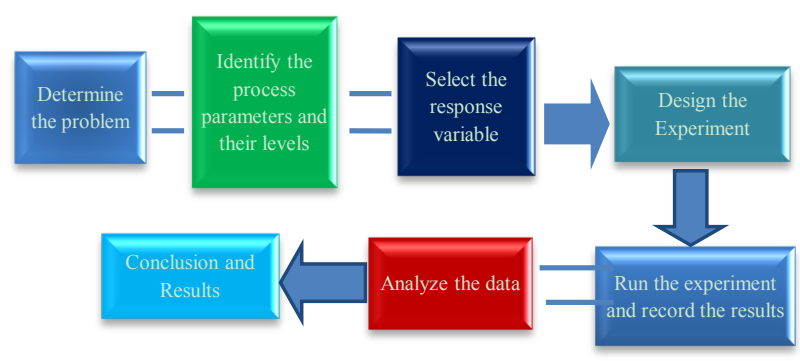

Figure 1. The Designed Experimental Sequence

\section{Experimentation}

\subsection{Surface Finish}

Whatever may be the manufacturing process, an absolutely smooth and flat surface cannot be obtained. The machine elements or parts retain the surface irregularities left after manufacturing the surface of a part is its exterior boundary and the surface irregularities consist of numerous small wedges and valleys that deviate from a hypothetical nominal surface. These irregularities are responsible to a great extent for the appearance of a surface and its suitability for an intended application of the component is usually understood in terms of surface finish, surface roughness, and surface quality. Heat exchanger tubes transfers' heat better when their surfaces are slightly rough rather than highly finished. However if a film of lubrication must be maintained between two moving parts, the surface irregularities must be small enough so that they do not penetrate the il film under the most severe operating conditions. Examples are bearings, journals, piston rings, helical and worm gears, cylindrical bores etc.

Factors Affecting the Surface Finish:

- Vibrations.

- Material of the work piece.

- Type of machining.

- Rigidity of the system consisting of machine tool, fix- ture, cutting tool and work.

- Type, form, material and sharpness of the cutting tool.

- Cutting conditions i.e. feed, speed and depth of cut.

- Type of coolant used.

\subsection{Analysis}

The procedure for the analysis of the surface roughness response variable was performed as follows.

- The response variable was chosen.

- The effects were calculated.

- Significant effects were chosen from the graph.

- The model graphs were analyzed.

Adding more parameters including material properties and other process parameters like hatch patterns, envelope temperature would result in an accurate and useful model to predict surface finish. A model with increased number of levels and a random effects model can be used to provide more insight on the sensitivity of surface finish to process parameter variation. Future advances in surface finish could include better post-processing techniques and improvements in the FDM hardware and the control system. For analyzing the surfaces we use the OPTICAL PROFILE PROJECTOR. This is an instrument used for measuring angles, pitches, and other related linear and angular measurements. It basically works on the principle of Optics.

\section{Results and Discussion}

Surface Roughness (Rz) of a tabulated data with parameters Sample Length (X) and Heights of peaks and valleys (Y) is calculated and Surface Profile is drawn by taking various combinations of Layer Thickness and Build Orientation.

Also the variation of Surface Roughness with both Layer Thickness and Build Orientation keeping one of the last two constant, the values are tabulated and plotted.

\section{Results}

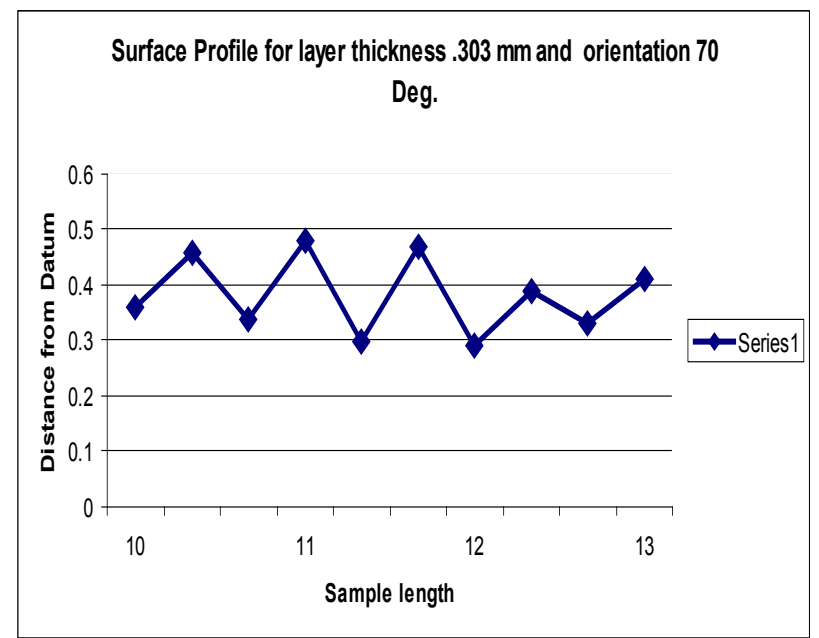

Figure 2. The variation of datum over the sample length with layer thickness 0.303 


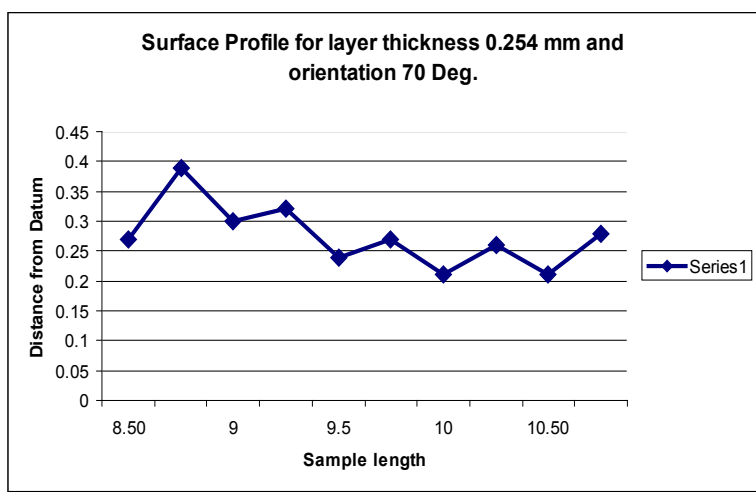

Figure 3. The variation of datum over the sample length with layer thickness $0.2547=2.12 \mu \mathrm{m} .36 \mu \mathrm{m}$

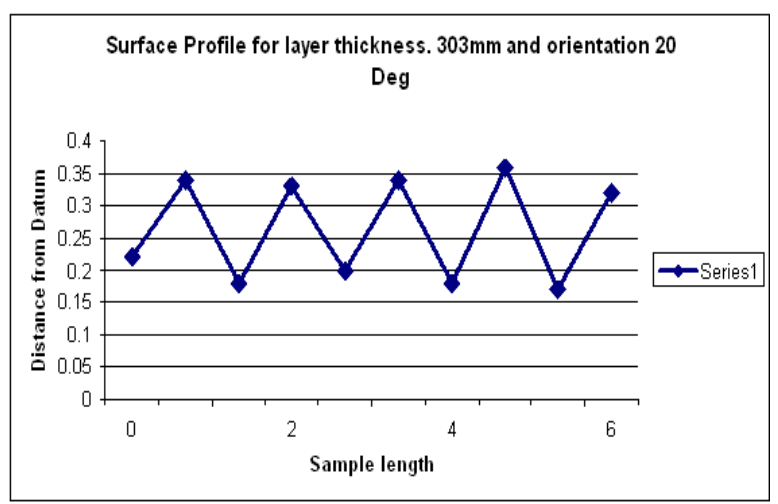

Figure 4. The variation of datum over the sample length with layer thickness 0.254 with $20^{\circ}$ orientation

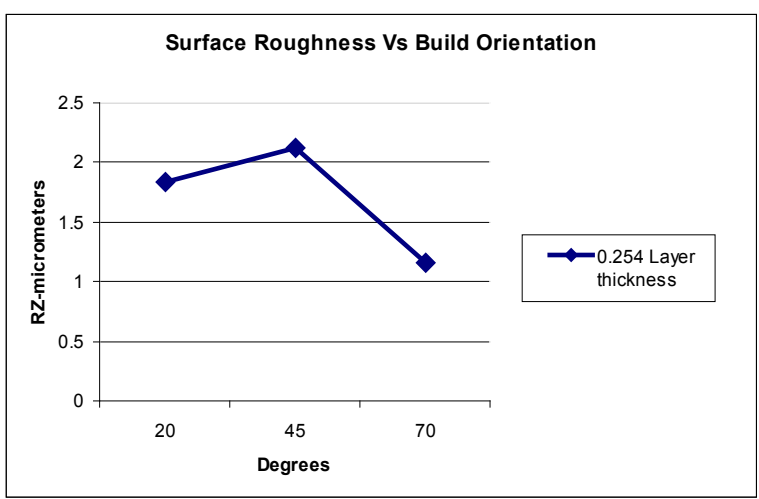

Figure 5. Variation of Surface Roughness with Build orientation for $0.254 \mathrm{~mm}$ Layer Thickness

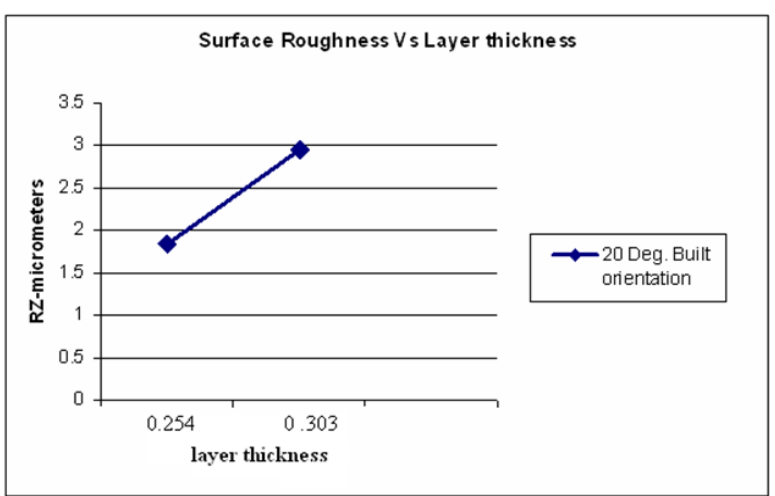

Figure 6. Variation of Surface Roughness with Layer Thickness for 20 Deg Build Orientation

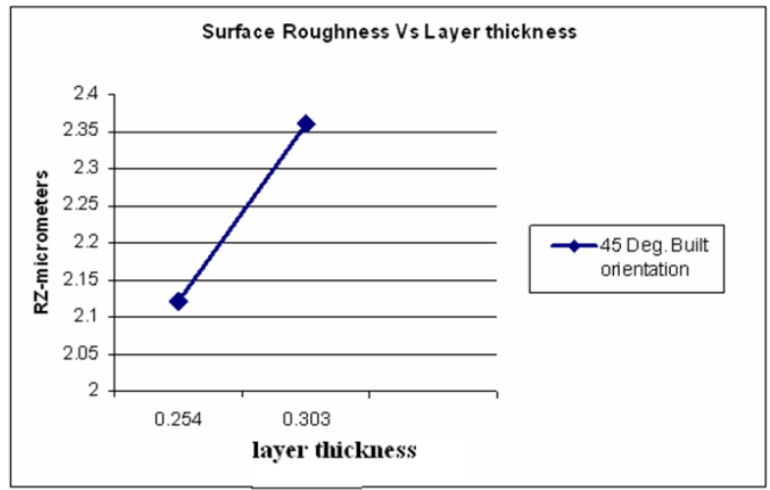

Figure 7. Variation of Surface Roughness with Layer Thickness for 45 Deg Build Orientation

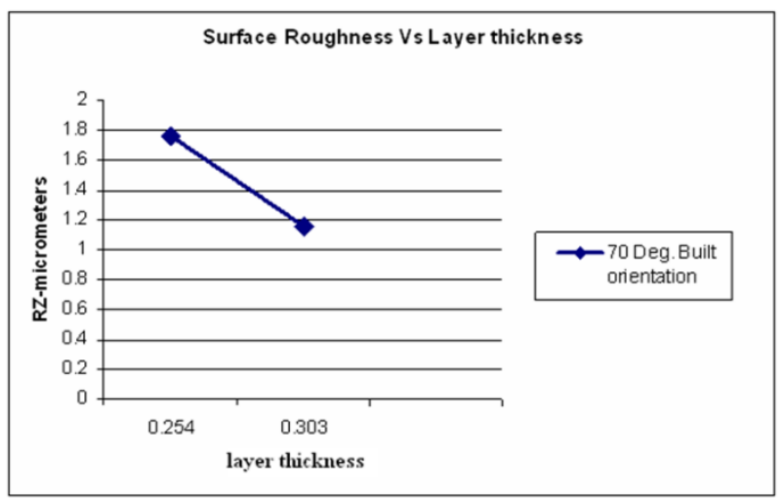

Figure 8. Variation of Surface Roughness with Layer Thickness for 70 Deg Build Orientations

\section{Discussion}

- From the graph 5 we can observe that at this layer thickness the roughness value $\mathrm{Rz}$ increased slightly and then started reducing accordingly with the increase in orientation.

- From the graph 6 we can observe that as the layer thickness is increased, the roughness value also increased.

- From the graph 7 we can observe that as the layer thickness is increased, the roughness value also increased.

- From the graph 8 we can observe that as the layer thickness is increased the roughness value decreased.

\section{REFERENCES}

[1] Koren.Y, "Computer Control of ManufacturingSystems", McGraw-Hill Publications, Singapore, 1983

[2] Kochan.D, "Solid Freeform manufacturing-Possibilities and Restrictions", Computers in Industry 20, pp. 133-140, 1992

[3] Chua.C.K, "Three-dimensional Rapid Prototyping Technologies and key Development Areas", Computing and Control Engineering Journal 5 (4): 200-206, 1994

[4] Dolenc.A, "An Overview of Rapid Prototyping Technology in Manufacturing", Otaniemi, TKO-B116, ISBN 951-22-2123-3, Helsinki University of Technology, Finland, 
1994

[5] Wohlers.T, "Future Potential of Rapid Prototyping and Manufacturing around the World", Rapid Prototyping Journal, vol. 1, pp.4-10, 1995

[6] Ashley, Steven, "Rapid Prototyping is Common of Age", Mechanical Engineering 117, No.7, pp.34-43, 1995

[7] Kochan.D and C.K.Chua., "State-of-the art and Future Trends in Advanced Rapid Prototyping and Manufacturing", International Journal of Information Technology 1(2): 173-184, 1995

[8] Kai Chua Chee, and Fai Leong Kah., "Rapid Prototyping: Principles and Applications in Manufacturing", John Wiley \& Sons, N Y, USA

[9] Pham.D.T, and Gault.R.S, "A comparison of Rapid Prototyping Technologies”, Int. J. Mach. Tools Manf. 38, pp. 12571287, 1998

[10] "Solid Modeling and Rapid Prototyping", Handbook of Solid Modeling, McGraw-Hill Publication, New York, pp. 19.1 19.20

[11] Nale et al. have made a time; cost and accuracy comparison in case of investment casting tooling produced using SLA technique, 1996

[12] Agarwala et al. made an attempt to enhance structuralstrength of FDM parts through fused deposition ceramic [FDM] and fused deposition metal [FDM Met], 1996
[13] Susila studied the problem of optimization byconsidering the direction of model build up. They found that the choice of correct orientation resulted in minimum build time 1997

[14] Diane et al. measured Ra values of SLA parts andconcluded that layer thickness and part orientation are important parameters, 1997

[15] Anita studied the applicability of the method of surface grinding problems, 1998

[16] Armillottta et al. conducted experimental study to evaluate surface roughness values as a function of layer thickness, build orientation, road width and raster angle for as FDM Manufactured part, 1999

[17] Anita et al. studied the influence of process parameters on quality of prototypes in FDM using Taguchi technique, 2000

[18] Bharath et al. proposed that the best possible surface finish on an FDM part can be obtained by choosing the optimal FDM process parameters. They carried out some fractional factorial experiments considering layer thickness, road width, air gap, build orientation and model temperature as process parameters, 2000

[19] Gantham et al. studied the surface roughness of FDM parts considering layer thickness; build orientation edge profile (elliptical), layer composition and sub-parameters. They carried out a no. of experiments and measured the surface roughness of upward and downward surfaces. Order of surface roughness value $(\mathrm{Ra})$ Reported by them is 1000 micro in. (25 um) 